\section{Acute heart failure}

Editor - We are writing to express our concern at a misconception alluded to by Cleland, Yassin and Khadjooi (Clin Med February 2010 pp 59-64). The authors state that 'patients with acute cardiogenic pulmonary oedema cannot lie flat so, unless the patient is ventilated, myocardial infarction (MI) should be managed with thrombolysis, and unstable angina with judicious doses of nitrates'.

This is outdated advice. Primary percutaneous coronary intervention can be carried out in patients with pulmonary oedema or cardiogenic shock - this is precisely the treatment they need to give them the best chance of survival, and it would be wrong to deny them this because of a misunderstanding of what is technically possible.

It is perfectly feasible to perform angioplasty in the semi-recumbent position, especially if via the radial route, in patients with acute pulmonary oedema and even in those requiring non-invasive ventilation. Clearly it is more technically difficult than performing angioplasty in a supine stable elective patient and angiographic projections need to be modified. The X-ray image intensifier or flat detector is positioned caudally to obtain an anteroposterior cardiac image, and it may be difficult to obtain true caudal views of the heart (as the X-ray equipment cannot be positioned yet more caudally to acquire true caudal views). However, an experienced interventional cardiologist would not shy away from this challenge. These high risk patients have most to gain from primary angioplasty and they should be offered this rather than thrombolysis, which is now regarded as a 'second best' treatment for acute MI.

There is much useful information in Cleland et al's article, however this misconception required clarification.

\section{ALICE WOOD}

ST5 cardiology

Norfolk and Norwich University Hospital

ELVED ROBERTS

Consultant interventional cardiologist Glenfield Hospital, Leicester

\section{Care closer to home - a changing role for physicians}

Editor - I read Linda Patterson's editorial (Clin Med February 2010 pp 4-5) with great interest. I am pleased to see that general practitioners with a special interest (GPwSI) did receive a mention albeit a brief one.

There are several experienced GPwSIs working in my locality in the field of gastroenterology and endoscopy. In my view both hospital trusts and primary care trusts (PCTs) have failed to utilise this workforce effectively: they have, in effect, been regarded as 'just another pair of hands'.

The government policy to deliver services closer to the patient's home is to be welcomed. There is now a new opportunity for PCTs to revisit service design which should permit GPwSIs (perhaps with nurse practitioners) to deliver clinical services from community premises. This would free up time for consultants to deal with bowel cancer screening as well as more complex and difficult cases. However, it is vital that GPwSIs liaise closely with consultant colleagues to ensure that the service design is sound and that the patient journey is appropriate and, above all, safe. Other issues such as training and governance need addressing carefully. The new GPwSI job description in endoscopy together with ongoing appraisal and revalidation (which is currently being developed) will look after this.

The new challenge therefore is not to deliver more of the same locally but to reexamine service design and use the available workforce more effectively. In doing so clinicians will work better together and their patients ultimately will get a better and timelier service.

MICHAEL AH COHEN

GP and GPwSI Gastroenterology

Westbury on Trym Primary Care Centre

Westbury on Trym, Bristol

\section{Care closer to home is not what the NHS needs}

Editor - Linda Patterson's editorial claims that 'More community working should lead to better management of chronic disease. This is the future' (Clin Med February 2010 pp 4-5). I hope not. I think it is regrettable that the 'care closer to home' mantra has somehow hypnotised us into presupposing the existence of some physical (or maybe metaphysical) barrier between hospital and community, with prejudices reinforced by inflammatory language. ${ }^{1}$ Policy it may be, but if it is bad policy we should have nothing to do with it.

At a time of economic crisis in the NHS we must husband resources. Small shops, while convenient for their users, are inefficient, as supermarket analysis proves. The network of community hospitals that sustained the NHS until the 1980s was largely closed down because it was unaffordable. To recreate it with new community hospitals or polysystems at huge capital cost (not least if projects require large private finance initiative repayments) is madness. What may be more convenient for some service users may be less convenient for others, as became apparent with a proposed network of musculoskeletal independent treatment centres in northwest England. ${ }^{2}$ The idiocy of the approach is exemplified by one of my patients who, told by their general practitioner (GP) that the community service was more convenient (because it was in the community), pointed out that it was two bus rides away when the district hospital was within five minutes' walk. If patients have to travel to another general practice where the specialist does clinics what difference is it to travelling to the hospital? Except in widely dispersed rural districts there is none. Gains to patients of local access to specialists may be largely offset by the inconvenience of multiple appointments because investigations such as X-rays cannot be organised 'in the community' on a one-stop basis.

We have become so focused on the public getting what they think they want that we have forgotten the needs of services and those who work in them. Why should I waste an hour a day travelling between under-resourced sites, thus reducing the number of patients I can see? I did outreach clinics in GP surgeries in the 1980s and abandoned them because they did not work. How will my multidisciplinary teams accompany me without a team bus? What about my inpatients and those I will not be able to see for my colleagues as I am no longer on the hospital site? How will I discuss cases with others, and they with me? If 
I am speeding around the community doing rheumatology clinics, how can I manage my rehabilitation unit? Multi-tasking is possible on one site, but not on many. Trainee teaching will collapse as the diversity of casemix, a virtue of service concentration, will be lost. The opportunity to collect cases for clinical trials will dissipate. Departmental morale will collapse. A two-tier service of superspecialist care in big teaching centres and barefoot specialist care elsewhere will develop. These are not my arguments alone; I asked my chronic disease 'focus group' (our local National Rheumatoid Arthritis Society network group) whether they would prefer to be seen by me in the hospital clinic or in their own GP surgeries. Without exception they expressed a preference to be seen at the hospital, citing many of the above concerns. Ask the wrong people and you get the wrong answer.

Concentration brings benefits. The clearest example of this is surgical; in the first world war facial injury care for Great Britain and the Dominions was concentrated in one hospital (mine, as it happens) and the advances in plastic surgery thereby generated were unmatched on the continent where facial injury was dealt with in a fragmented way. Furthermore the patient support that grew from this obviated the need for a self-help group, whereas in France 'les gueules cassées' developed because of the isolation and dispersion of sufferers. ${ }^{3}$ To create a specialist diaspora will recreate the disadvantages of dilution. We must learn from history.

Lastly, Care in the Community often means very little, or no, care. As social service budgets contract and input from carers diminishes we have already seen the adverse effects and must do everything we can to avoid this in medicine.

That is not to say that hospital-based care is cheap or that we should not look for ways of making it cheaper, for example by running telephone clinics for those on longterm follow-up. As Patterson points out, hospitals are encouraged to maximise income, while PCTs try to limit access because Payment by Results (PbR) tariffs are unaffordable. But we do not need to disperse specialists to address this; as the musculoskeletal services in Stoke and Bolton have shown it may be possible to avoid sub- stantial transactional costs by changing management from acute trust to PCT without necessarily altering the physical structure of the service. We should also remember that those services turning a profit in an acute trust (rheumatology outpatients is one) will prop up the loss leaders (acute medicine is one). So pulling out profitable services may compromise the whole of acute hospital-based care - unless the purchaser-provider split is abolished, which, for me, would be the essential and final outcome of Teams without Walls. ${ }^{4}$

I firmly believe that care closer to home is a concept based on flawed research and the turning of a blind eye to economic reality. Specialist medicine as a whole will be seriously damaged if we fail to examine its risks.

ANDREW BAMJI

Past president, British Society for Rheumatology (2006-8)

Consultant rheumatologist Director, Elmstead Rehabilitation Unit Queen Mary's Hospital, Sidcup, Kent

\section{Conflict of interest}

$\mathrm{AB}$ is employed by an acute trust.

\section{References}

1 Stoate HGA, Jones B. Challenging the citadel: breaking the hospitals' grip on the NHS. London: Fabian Society, 2006.

2 British Society for Rheumatology. Response of the British Society for Rheumatology to the consultation document 'Improving our patients' experience of healthcare in Cumbria and Lancashire: clinical assessment, treatment and support centres'. March 2007 http://sidcuprheum.org.uk /bsractionplan/bsr\%20response\%20lancs\% 20icats.doc

3 Harold Gillies: surgical pioneer. Trauma 2006;8:143-56.

4 Royal College of Physicians. Teams without walls. The value of medical innovation and leadership. London: RCP, 2008.

\section{In response to both}

I agree with Dr Cohen that general practitioners (GPs) with a special interest have an important role. It is essential that they feel part of the specialist service and participate in audit, continuing professional development and so on with specialist colleagues.
They also need to be able to discuss patients easily with consultants and to access more specialist opinion when needed, as well as bringing their expertise as to how patients can be managed in the community.

Dr Cohen also makes the point that the challenge is not to deliver more of the same just in a different location - which very well answers Dr Bamji's concerns. Moving expertise into the community, working more closely with GP colleagues, community nurses and other professionals to deliver consultant input in a different way is not just an argument about geography. There are undoubtedly logistical difficulties in providing services in different places, but these can be overcome (and many consultants already deliver outpatient services in locations away from their home base). The point of consultants working in community settings is to develop better pathways of care which are more joined up across the old primary-secondary care boundaries and to truly build Teams without Walls.

\section{LINDA PATTERSON OBE}

Consultant physician Medicine for Older People Yarnspinners Health Centre

Nelson, Lancashire

\section{Managing capacity and demand across the patient journey}

Editor - Walley and colleagues recently highlighted the problem of reduced bed capacity which has an impact on coping with healthcare demand (Clin Med February 2010 pp 13-5).

I would like to comment on the longterm planning and that bed requirements are based on average demand and average length of stay, the author felt that this can create a problem as once there is random variation in demand and staff capacity, bed shortages will occur. I do not feel that we have a bed shortage in England. However, the discharge process is patchy and lengthy and there is a lack of coordination between hospital staff or secondary care and primary care as well as between NHS and social services.

I agree with the author that a 'systems' approach is the only solution where healthcare staff and social services, primary and 